ORIGINAL ARTICLE-

Volume 12 Issue 12020

DOI: $10.21315 /$ eimj2020.12.1.6

ARTICLE INFO

Submitted: $12-02-2020$

Accepted: 21-02-2020

Online: 10-04-2020

\section{Profiling of Medical Graduates of Universiti Sains Malaysia: What the Data Said}

\author{
Mohd Zarawi Mat Nor ${ }^{1}$, Ahmad Fuad Ab. Rahim', Mohamad Najib \\ Mat Pa ${ }^{1}$, Kamarul Aryffin Baharuddin ${ }^{2}$ \\ ${ }^{1}$ Department of Medical Education, School of Medical Sciences, \\ Universiti Sains Malaysia, Kelantan, MALAYSIA \\ ${ }^{2}$ Department of Emergency Medicine, School of Medical Sciences, \\ Universiti Sains Malaysia, Kelantan, MALAYSIA
}

To cite this article: Mat Nor MZ, Ab. Rahim AF, Mat Pa MN, Baharuddin KA. Profiling of medical graduates of Universiti Sains Malaysia: what the data said. Education in Medicine Journal. 2020;12(1): 53-63. https://doi.org/10.21315/eimj2020.12.1.6

To link to this article: https://oi.org/10.21315/eimj2020.12.1.6

ABSTRACT

Generally, this tracer study determines the profiling of medical graduates of Universiti Sains Malaysia (USM) in duration of 10 years (1999-2000). Specifically, it emphasises on the graduates' employment information, areas of specialisation, engagement and contribution at local, national and international levels as well as personal career development. The respondents were identified from the USM academic affairs database. The present study utilises a cross-sectional research design which involves 177 respondents. An online survey was employed to gather the data which then analysed using Statistical Package for the Social Sciences (SPSS) version 22. The findings show that the majority of the respondents have been involved in the medicine profession as a full-time medical practitioners since their graduation from USM. They have also advanced their study in clinical and non-clinical areas in other medical schools world-wide having either a Master of Medicine or Master of Science qualification. Besides that, respondents have also contributed professionally at the local, national and international levels. Fellowships, sub-specialty, advanced diploma and professional courses are among the preferred options in enhancing their personal career development. USM medical graduates actively involved in the medical fields. It is shown that they have a robust intention in the same field where they are endlessly serving ever since they have graduated.

Keywords: Medical graduates, Tracer study, Profiling of medical students

\section{INTRODUCTION}

A tracer study can be defined as an impact assessment tool where the impact on target groups is traced back to specific elements of a project or programme. In educational research, the tracer study is regarded as a study to trace graduates of higher education institute. "Graduate surveys", "alumni researches", "graduate career tracking" 
or "follow-up study" are other terms for it. Researchers used the word tracer study because this study focused on tracing the movement of medical graduates in terms of their involvement after they have left the university. The graduate surveys are popular tool for analysis of the relationship between higher education and work. They provide quantitative-structural data on employment and career, the character of work and related competencies and information on the professional orientation and experiences of their graduates (1). Apart from that, the tracer study may also answer questions such as (1):

a. What are the retrospective views of graduates on higher education based on their career experiences?

b. To what extent do graduates consider their education and training as a wastage or an opportunity?

c. How are the outcomes of curriculum aiming to create new types of learning and qualifications to prepare newly emerging types of occupation and work tasks?

d. How broad or narrow is knowledge fostered in individual degree programmes in comparison to occupational tasks and major occupations?

Higher educational institutions worldwide have carried out many tracer studies (16). All of them concentrated on themes of tracing their students after they graduated from the university (4), assessing the significant of the curriculum with the current job (2), and gaining information on how to improve teaching and learning process from the graduates' perspective $(7,8)$. For instance, a study had been conducted which aimed at examining the connection between curriculum and manpower development in manufacturing sector $(6,9,10)$. A similar study was also conducted to investigate the links between higher education and graduate employment in Europe, Latin America, Asia and Africa (3).
Ministry of Education Malaysia had also conducted similar exercise in 2013 in order to explore graduates' perceptions of the programme which are implemented by the university, identify the facilities and services utilised while they were studying, and discern the profiling of jobs embraced after study completed $(11,12)$. Specifically, numerous higher educational institutions have conducted various studies to trace their exstudent. The studies also attempted to detect the graduates' tendency to further study (13), specificities chosen (14) and the willingness to continue their service in the medical fields (15).

In the context of USM, there are 30-150 medical graduates annually, yet we do not have the latest empirical data about them since they graduated. Therefore, this exercise is critical to numerous people such as administrators, lecturers and others who are related with the student's affairs. Despite the importance of data on the alumni movement, no similar study has ever been conducted in the School of Medical Sciences (SMS), USM. This has led to a lack of the latest data on such matter. Thus, it is expected that the present study conducted not only will be able to provide a comprehensive data on medical graduate but also will close the existing gap of the data.

Considering the current themes of the tracer studies, this study aims at seeking comprehensive data on medical graduates. In addition, demography characteristics, employment status, engagements and contributions, and personal career development are also emphasised in this study. Specifically, the study aims are to determine:

a. The graduates' employment information.

b. The areas of specialisation.

c. The graduates' engagement and contribution of information at local, national and international levels.

d. The graduates' personal career development. 
e. To propose a current holistic database on medical graduates from USM.

\section{MATERIALS AND METHODS}

The present study applied descriptive research design. It describes the experiences of the graduates after completing their study including employment information, areas of specialisation, engagement and contribution. This research design is relevant in this study as the data are derived from questionnaires (16). A total of 177 medical graduates from USM were involved in the study. They were undergraduates and post-graduates who graduated from 1999 to 2000. This super-senior group of students were selected because of their ability to provide rich information on their career development where the junior students were unable to do so.

A validated questionnaire was utilised for the data collection. In order to produce an authorised questionnaire, content and face validity process have been performed by eight senior lecturers from the department of medical education. Apart from that, the Dean and the Deputy Dean of SMS were also involved as the final checkers. The questionnaire consists of five parts, which are personal information, educational information, employment information, area of specialisation, engagement and contribution, and personal career development.

The data collection process begins with the identification of the potential respondents by referring to the academic office of SMS and Malaysia Medical Association (MMA) records. These tasks' objectives were to trace the respondents' information such as the workplace. Once the basic information was obtained, official letters to their employers were issued to request the contact numbers and email addresses of their employees. At the end of this phase, a sufficient information about the potential respondents were obtained. The final step was to distribute the questionnaires using online interaction with the respondents. They were asked to answer the questionnaire and then return it upon completion. The data collection processes were performed from 1 June 2017 to 30 May 2018. The obtained data was analysed using SPSS programme. The findings were presented according to the arrangement of the research objectives.

\section{RESULTS}

Although 300 respondents had been contacted, only 177 (59\%) responded to the questionnaire. The data collected were classified and tabulated for analysis. Percentage and rank were the statistical tool utilised in interpreting the data obtained from the survey. The majority of the graduates; $91(51.4 \%)$ were females compared to $86(48.6 \%)$ of males as shown in Table 1. The marital status was such that the majority of the graduates were married 159 $(89.8 \%)$ compared only $18(10.2 \%)$ were not married. Of these, 151 (85.3\%) were Malay, followed by Chinese $12(6.8 \%)$, Indian 10 $(5.6 \%)$ and others $4(2.3 \%)$. Respondents were also asked to share their employment information. Table 2 presents that the majority of respondents are working full-time $164(93.0 \%)$ followed by studying full-time $7(4.0 \%)$ and are self-employed $6(3.0 \%)$.

To ensure that a profound information has been obtained, the areas of specialisation were categorised into two clusters which are Master of Medicine consisting of 19 subareas and Master of Science 5 sub-areas. Table 3 shows that the number of Master of Medicine and Master of Science are $140(79.0 \%)$ and $37(21.0 \%)$ respectively. Among the sub-areas in Master of Medicine, Emergency Medicine has become a prominent area of specialisation $29(16.4 \%)$ followed by Psychiatry $19(10.7 \%)$ and the lowest was Transfusion Medicine, Radiation Oncology, Community Health and Master's in Enforcement Law 1 (0.6\%). 
Table 1: Profile of participants $(n=177)$

\begin{tabular}{lcc}
\hline \multicolumn{1}{c}{ Variable } & & $\boldsymbol{n}(\%)$ \\
\hline Gender & Male & $86(48.6)$ \\
& Female & $91(51.4)$ \\
\hline \multirow{2}{*}{ Marital status } & Married & $159(89.8)$ \\
& Not married & $18(10.2)$ \\
\hline \multirow{2}{*}{ Race } & Malay & $151(85.3)$ \\
& Chinese & $12(6.8)$ \\
& Indian & $10(5.6)$ \\
& Others & $4(2.3)$ \\
\hline
\end{tabular}

Table 2: Employment information $(n=177)$

\begin{tabular}{lc}
\hline \multicolumn{1}{c}{ Current employment } & $\boldsymbol{n}(\%)$ \\
\hline Working full-time & $164(93.0)$ \\
Studying full-time & $7(4.0)$ \\
Self-employed & $6(3.0)$ \\
\hline
\end{tabular}

Table 3: Area of specialisation

\begin{tabular}{lcc}
\hline Area of specialisation & Sub-area & $\boldsymbol{n}(\%)$ \\
\hline & Anaesthesia & $9(5.1)$ \\
Internal medicine & $6(3.4)$ & $29(16.4)$ \\
Emergency medicine & $5(2.8)$ \\
Ophthalmology & $9(5.1)$ \\
Paediatrics & $14(7.9)$ \\
Obstetrics and Gynaecology & $3(1.7)$ \\
Master of Medicine & Orthopaedic & $8(4.5)$ \\
Ot9.0) & Otolaryngology & $2(1.1)$ \\
Psychiatry & $19(10.7)$ \\
Radiology & $10(5.6)$ \\
Surgery & $10(5.6)$ \\
Family Medicine & $4(2.3)$ \\
Paster's in Enforcement Law & $3(1.7)$ \\
Transfusion Medicine & $4(2.3)$ \\
Community Medicine & $1(0.6)$ \\
Radiation Oncology & $1(0.6)$ \\
Community Health & $1(0.6)$ \\
& $1(0.6)$ \\
\hline
\end{tabular}


Table 3: (continued)

\begin{tabular}{ccc}
\hline Area of specialisation & Sub-area & $\boldsymbol{n}(\%)$ \\
\hline & Integrated Neuroscience & $2(1.1)$ \\
Master of Science & Public Health & $22(12.4)$ \\
$37(21.0 \%)$ & Medical Education & $10(5.6)$ \\
& Clinical Anatomy & $2(1.1)$ \\
& Medical Statistic & $2(1.1)$ \\
\hline
\end{tabular}

Participants were requested to share their engagement and contribution in four domains; health care service, academic, research and others. Each domain was measured in three levels of achievement which were local, national and international. Figure 1 shows that there were a total of 922 engagement and contribution exercises in these domains, evidenced by the respondents. Of these, health care service 405 (43.9\%), academic 181 (19.6\%), research 178 (19.3\%) and others 158 $(17.1 \%)$. Among the domain of health care service, hospital care was the highest 133 with the contribution at the local, national and international levels were $56.4 \%$, $38.3 \%$ and $5.3 \%$ respectively, followed by primary health care 79 with $72.1 \%, 22.8 \%$ and $5.1 \%$. While community care 79 with $76.0 \%, 21.5 \%$ and $2.5 \%$, followed by specialised service 73 with $64.4 \%, 31.5 \%$ and $4.1 \%$. The lowest is pharmaceutical care and utilisation 41 with $73.2 \%, 17.1 \%$ and $9.7 \%$ (Figure 2).

Academic domains consist of three subdomains, whereby full-time and parttime academician 80, consultation 43. In terms of level of engagement and contribution at local, national and international were $61.2 \%, 33.8 \%$ and $5.0 \% ; 50.0 \%, 15.0 \%$ and $35.0 \% ; 39.5 \%$, $53.5 \%$ and $7.0 \%$ for full-time, part-time academicians and consultation, respectively (Figure 3). There were two sub-domains in the research domain such as collaborative/ participatory of research and action research. These domains each contributed 100 and 64, respectively. In terms of level of achievement, which are local, national and international levels, there were $51.0 \%$, $18.0 \%$ and $31.0 \%$, and $40.6 \%, 45.3 \%$ and $14.1 \%$ for collaborative/participatory of research and action research, respectively (Figure 4).

Representing other domains were volunteer work 75 , non-government organisation (NGO) 69 and politician 14. In terms of level of achievement, at local, national and international levels there were $58.7 \%$, $36.0 \%$ and $5.3 \% ; 56.5 \%, 36.2 \%$ and $7.3 \%$ for volunteer work and NGO, respectively. While $78.5 \%$ and $21.5 \%$ of politician involved at local and national levels. No one of politician involved at international level (Figure 5). 


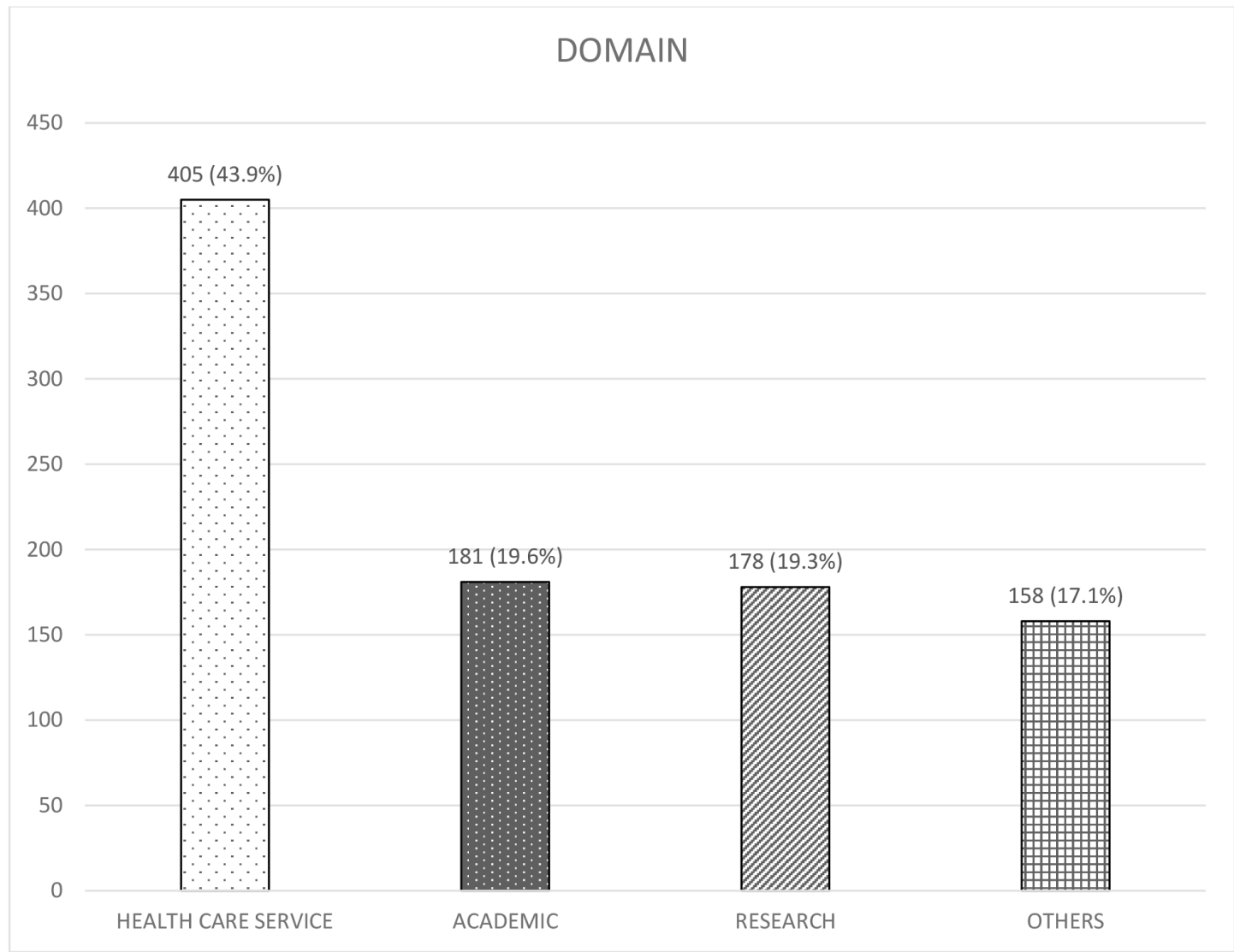

Figure 1: Engagement and contribution.

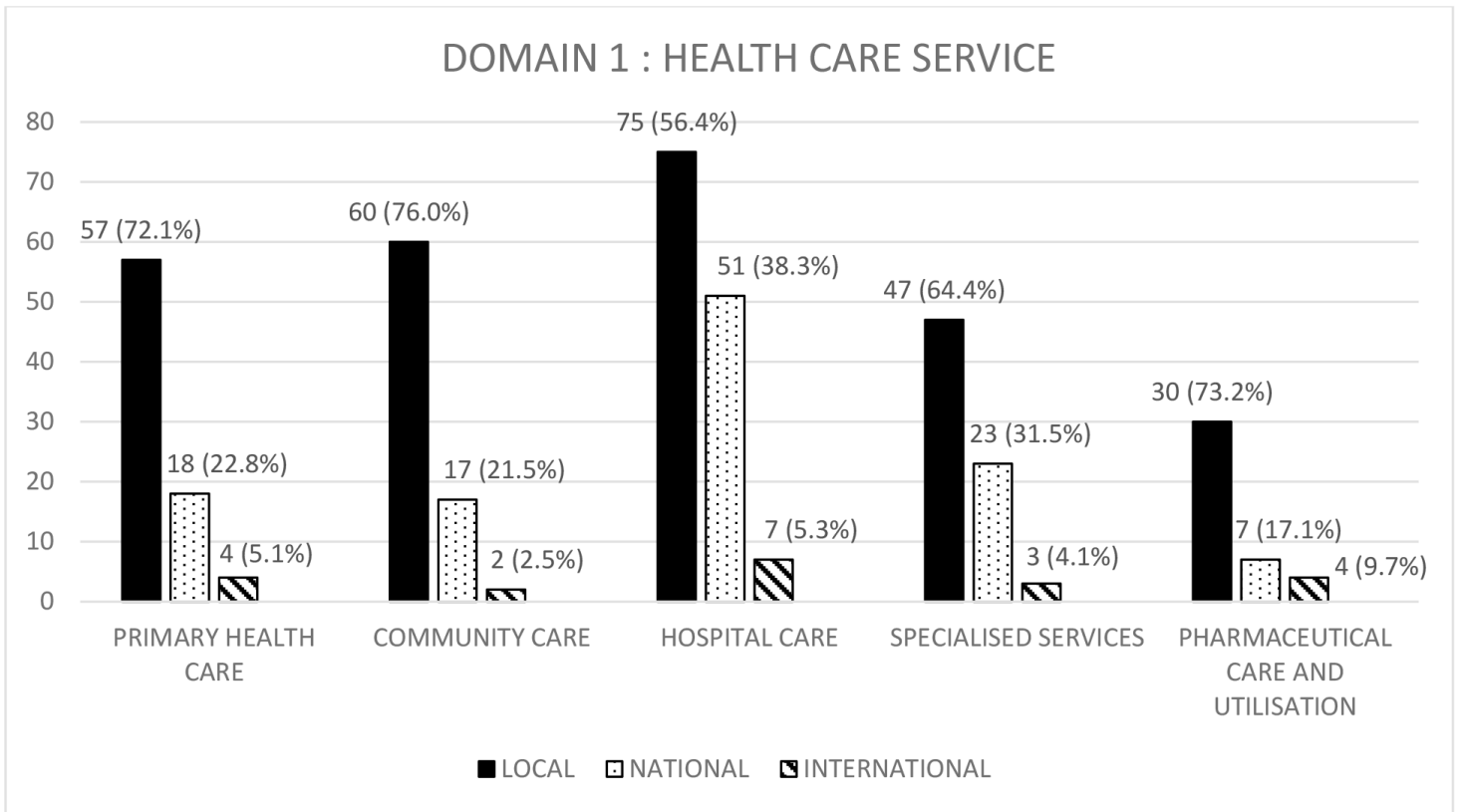

Figure 2: Engagement and contribution of health care service domain. 


\section{DOMAIN 2 : ACADEMIC}

60

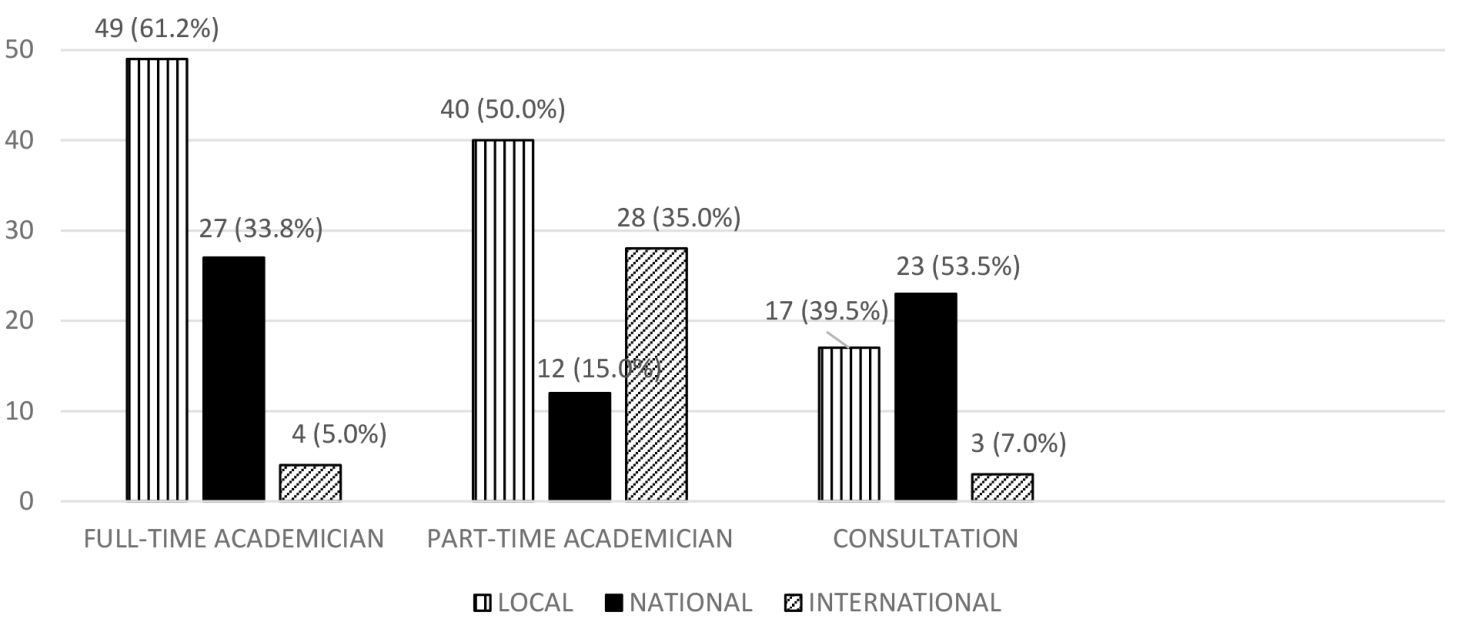

Figure 3: Engagement and contribution of academic domain.

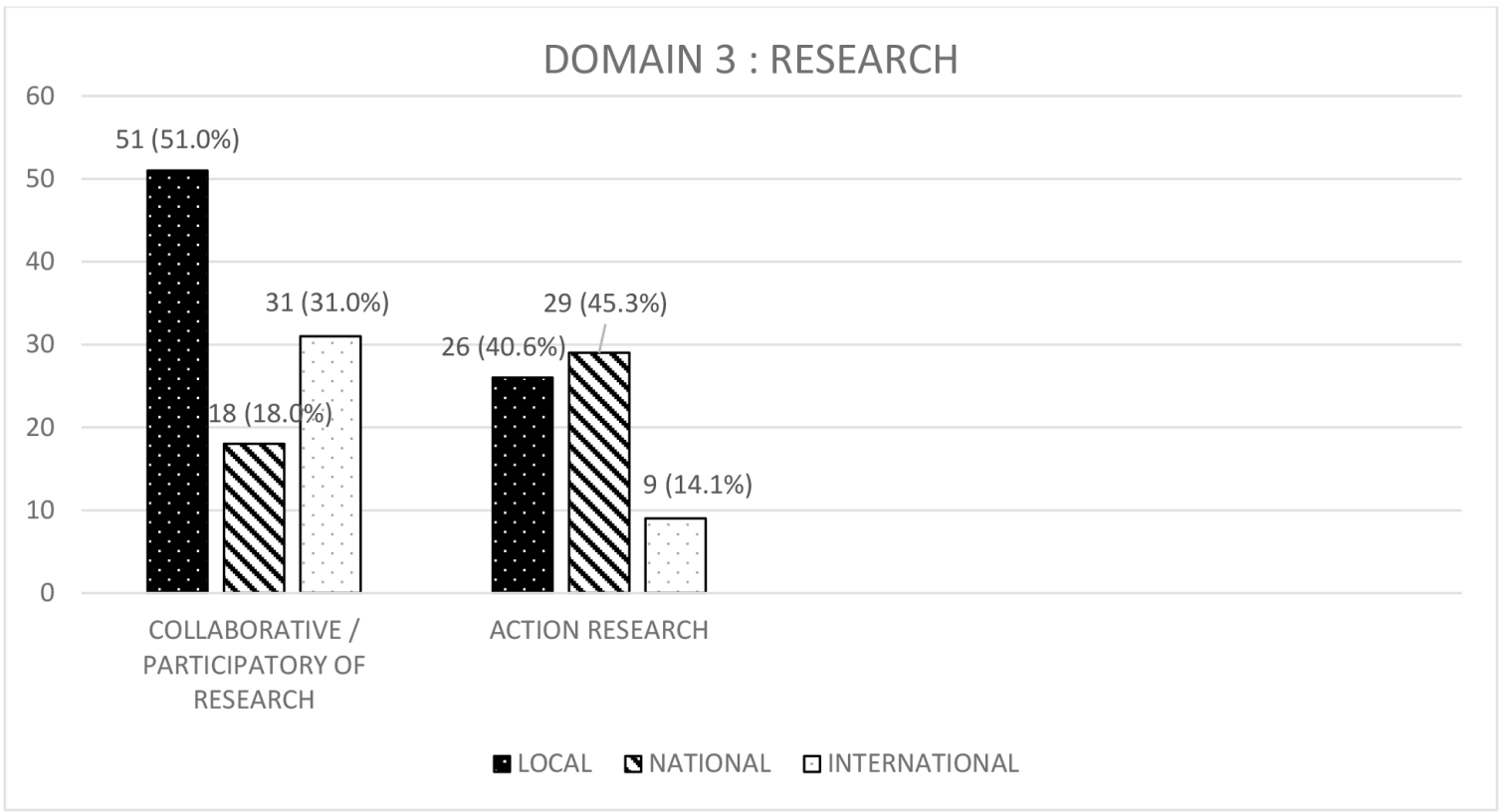

Figure 4: Engagement and contribution research domain. 


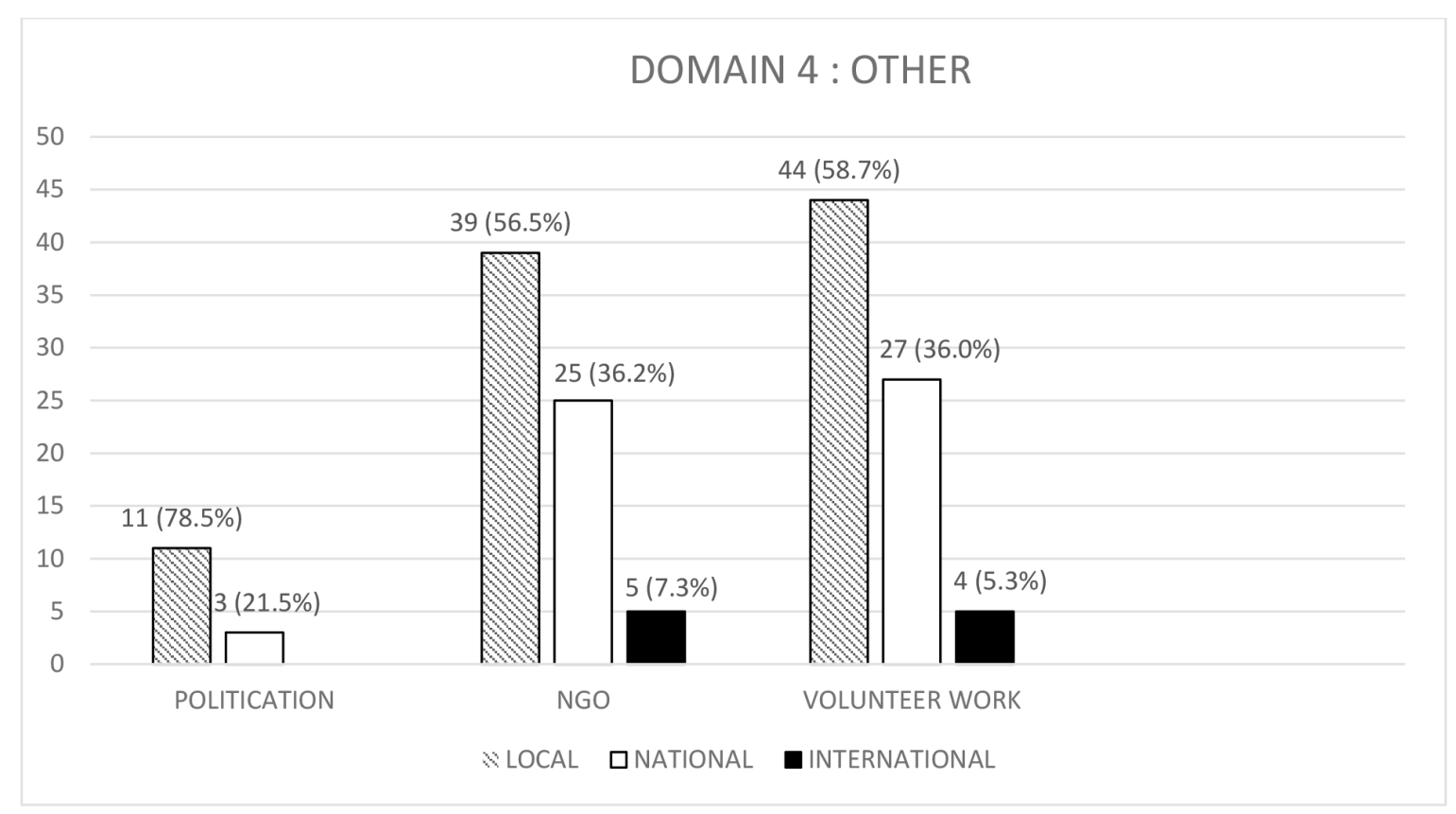

Figure 5: Engagement and other contributions domain.

Participants were also requested to share their study advancement covering fellowships, sub-speciality, advanced diploma and professional courses. Of the total 177 participants, those who were on sub-speciality study was 60 (34.0\%), followed by fellowship $52 \quad(29.0 \%)$, professional course $35 \quad(20.0 \%)$ and advanced diploma 30 (17.0\%). Singapore, Australia, USA and Switzerland were the chosen destinations for fellowship study. Meanwhile, most sub-specialty study was completed in Australia and United
Kingdom. Then Singapore, University of California and Switzerland for advanced diploma.

Apart from that, other professional courses have also been done in USA, Amsterdam, Singapore, Philippines, Hong Kong, United Kingdom, China, Australia and Thailand (Figure 6). In terms of the reasons for the admission acceptance to the above stated study, interest and relevant to the position held were the among the responses given. 


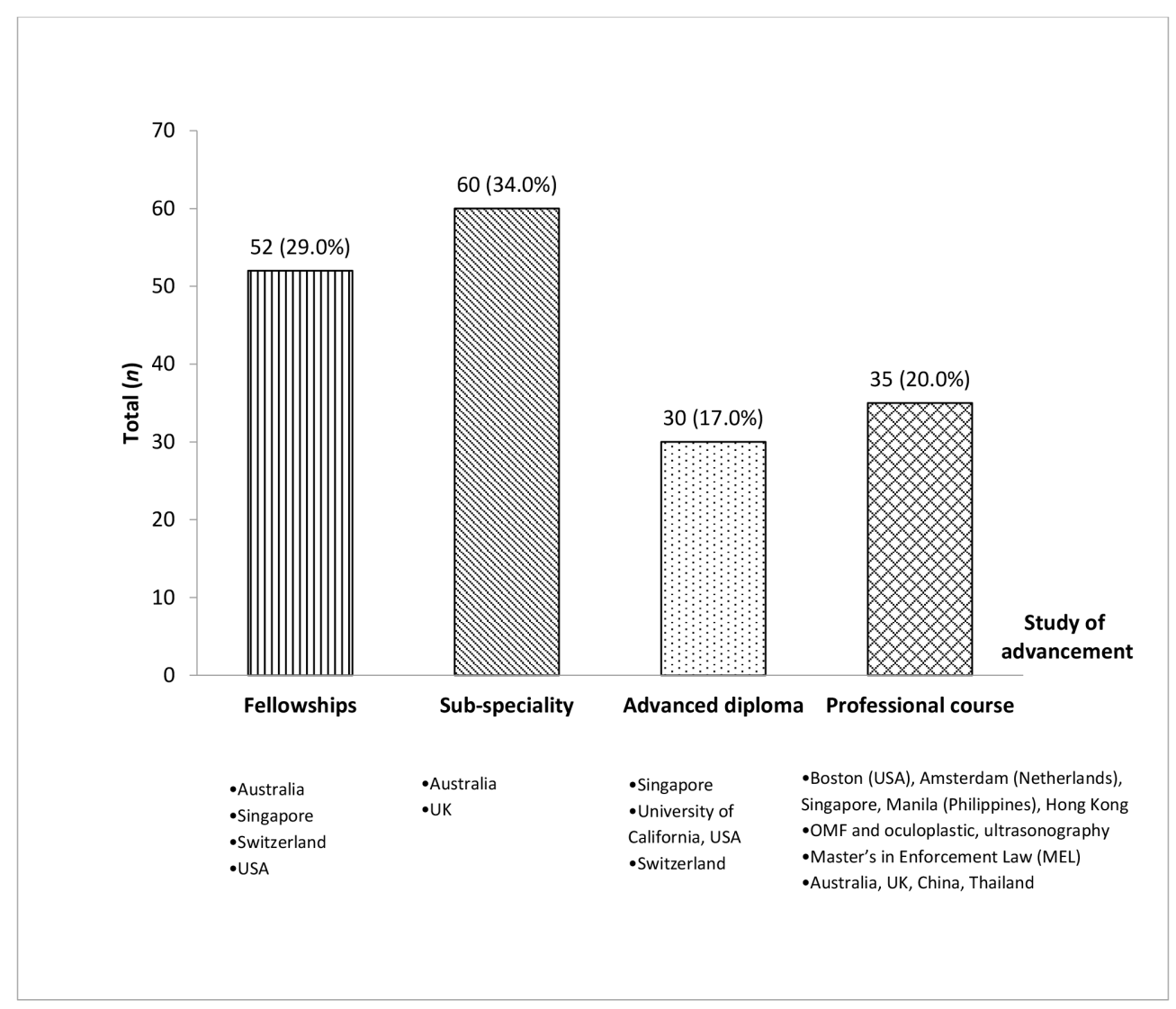

Figure 6: Personal career development.

\section{DISCUSSION}

The purpose of the present study is to recommend a comprehensive figure of medical graduates from USM in the duration of 10 years (1999-2000). It includes employment evidence, areas of specialisation, engagement and contribution, and personal career development. Majority of the study population are females. This is aligned with the nature of the Malaysian's student in higher education institutions where the gender ratio is unbalanced (17). The findings showed that the USM medical graduates are actively involved in the medical fields. This is consistent with a previous study, where its graduates have a robust intention in the same field where they endlessly serve ever since they have graduated $(13,15,18)$.
Apart from that, the population of the study also practised life-long learning concept by voluntarily pursuing their study at postgraduate level in clinical and non-clinical areas. This result supports a study which highlighted that, ensuing further study is one of the popular options among graduated doctors $(14,19)$. This finding is aligned with another earlier study which noted that majority of their graduated medical students $(89.6 \%)$ have chosen surgery, medicine, paediatrics, and obstetrics and gynaecology as their selected specialties (14).

The data revealed that the USM medical graduates are well-recognised by other institutions worldwide through their expertise contribution in health care service, academic and research locally, nationally and internationally. This finding had supported the evidence that a professional 
doctor does not only focus on the core business as a physician but also actively engaged in other fields at various level (20, 21).

Despite the interesting result of the study, the research has its limitations. Firstly, the study populations are limited to those who graduated in the duration of 10 years (19992000). Thus, the result does not represent a broad population. Secondly, the area of the study did not cover a broader spectrum, for instance, effectiveness of the curriculum was excluded from the work. Considering these limitations, the recommendations are as follows:

a. The SMS should update the status of their graduates from time to time.

b. Extends the scope of the tracer study to evaluate curriculum effectiveness in the students' perspectives.

c. Tracer study can also be conducted based on the batch of student to compare the results of different intake.

\section{CONCLUSION}

We found that the present study is considered to be very fruitful and is aligned with the school's aim to trace their graduates. Hopefully, the findings of the study are sufficient to provide a database on graduated doctors from the SMS in USM in order to enhance the alumni profile.

\section{ACKNOWLEDGEMENTS}

The study has been funded by USM via a short-term grant (USM/304/ PPSP/6315086). The authors would like to express undivided gratitude to USM for providing the fund to conduct the present study. Further appreciation goes to the SMS dean and the USM alumni for their continues support in completing the study.

\section{REFERENCES}

1. Schomburg H. Handbook for tracer studies. Germany: Centre for Research on Higher Education and Work, University of Kassel; 2003.

2. Maderazo JD. Tracer study of dentistry graduates of one higher education institution in the Philippines from 2008 to 2012. Asia Pacific Journal of Multidisciplinary Research. 2016;4(3):160-7.

3. Badiru EO, Wahome M. Conducting graduate tracer studies for quality assurance in east African universities: a focus on graduate students voices on quality culture. Journal of Education and Practice. 2016;7(6):174-81.

4. Mwakigonja AR. The Doctor of Medicine curriculum review at the School of Medicine, Muhimbili University of Health and Allied Sciences, Dar es Salaam, Tanzania: a tracer study report from 2009. BMC Med Educ. 2016;16(1):223. https:// doi.org/10.1186/s12909-016-0745-7

5. Mubuuke A, Businge F, Kiguli-Malwadde E. Using graduates as key stakeholders to inform training and policy in health professions: the hidden potential of tracer studies. African Journal of Health Professions Education. 2014;6(1):52-5.

6. Omeje K. Final report of tracer study research project on higher education and the demands of manpower development in the Nigerian manufacturing sector: an empirical study of Enugu and Nambra States. Institute for Development Studies University of Nigeria Enugu Campus Nigeria; 1998.

7. Istiningtyas L, Lukmawati L. Tracer study of the psychology faculty of UIN Raden Fatah Palembang in 2018: satisfaction of alumni and stakeholders on the implementation of Islamic psychology study programs. Jurnal Konseling dan Pendidikan. 2019;7(1):8-15. https://doi.org/10.29210/129200 
8. Suwardi S, Saleh K, Suharmanto S. Struktural analisis model proses pembelajaran dengan pendekatan kepuasan lulusan: studi kasus pada tracer study program studi administrasi bisnis. Admisi dan Bisnis. 2019;20(1):1-10. https://doi.org/ 10.32497/ab.v20i1.1421

9. Caminade LM, Flores LP, Sagarino EV. A tracer study on the employability status of the university of the immaculate conception accountancy graduates: implication of their academic training. International Journal of Education Research for Higher Learning. 2016;22(1):67-83.

10. Rogan M, Reynolds J. Schooling inequality, higher education and the labour market: evidence from a graduate tracer study in the Eastern Cape, South Africa. Development Southern Africa. 2016;33(3):343-60. https:// doi.org/10.1080/0376835X.2016.1153454

11. Hanapi Z, Nordin MS. Unemployment among Malaysia graduates: graduates' attributes, lecturers' competency and quality of education. Procedia-Social and Behavioral Sciences. 2014;112:1056-63. https://doi.org/ 10.1016/j.sbspro.2014.01.1269

12. Cervantes MLD. A tracer study on the employability of CBEA graduates (20102015) of La Consolacion University Philippines. International Journal of Business and Commerce. 2019;7(3):16-36.

13. Goel S, Angeli F, Dhirar N, Sangwan G, Thakur K, Ruwaard D. Factors affecting medical students' interests in working in rural areas in North India: a qualitative inquiry. PloS One. 2019;14(1):e0210251. https://doi.org/10.1371/journal.pone.0210 251

14. Alawad AAMA, Khan WS, Abdelrazig YM, Elzain YI, Khalil HO, Ahmed OBE, et al. Factors considered by undergraduate medical students when selecting specialty of their future careers. Pan Afr Med J. 2015;20:102. https://doi.org/10.11604/pamj .2015 .20 .102 .4715
15. Rezaei S, Hajizadeh M, Kazemi Karyani A, Soltani S, Asadi H, Bazyar M, et al. Determinants of willingness to practice medicine in underdeveloped areas: evidence from a survey on Iranian medical students. International Journal of Health Governance. 2019;24(1):31-41. https://doi.org/10.1108/IJ HG-06-2018-0026

16. Zulueta FM, Costales NEB. Methods of research, thesis-writing and applied statistics. Philippines: Navotas Press; 2003.

17. Jamil H, Shabudin AFA, Raman SR, Ling OP. Changing landscape of the Malaysian higher education: an overview of women's glass ceiling. In: Neubauer D, Kaur S, editors. Gender and the changing face of higher education in Asia Pacific. New York: Palgrave Macmillan; 2019. p. 145-65. https: //doi.org/10.1007/978-3-030-02795-7_10

18. Liu J, Zhu B, Mao Y. Association between rural clinical clerkship and medical students' intentions to choose rural medical work after graduation: a crosssectional study in western China. PloS One. 2018;13(4):e0195266. https://doi.org/10.13 71/journal.pone.0195266

19. Scanlan GM, Cleland J, Stirling SA, Walker K, Johnston P. Does initial postgraduate career intention and social demographics predict perceived career behaviour? a national cross-sectional survey of UK postgraduate doctors. BMJ Open. 2019;9(8):e026444. https://doi.org/10.1136/ bmjopen-2018-026444

20. Sharif H. Chekov, Ibsen and Flaubert's doctors: an ideo-historical literature essay on how the medical revolution of the 19th century changed the role of doctors. 2019. Available at: http://www.diva-portal.org/ smash/record.jsf?pid=diva2\%3A 1302422 \&dswid=1583393689412

21. Jones L, Moss F. What should be in hospital doctors' continuing professional development? Journal of the Royal Society of Medicine. 2019;112(2):72-7. https://doi .org/10.1177/0141076818808427 